Research article

Open Access

\title{
Risk of second primary cancer in men with breast cancer
}

\author{
Sacha Satram-Hoang, Argyrios Ziogas and Hoda Anton-Culver
}

Epidemiology Division, School of Medicine, University of California, Irvine, CA 92697, USA

Corresponding author: Hoda Anton-Culver, hantoncu@uci.edu

Received: 22 Sep 2006 Revisions requested: 13 Nov 2006 Revisions received: 21 Nov 2006 Accepted: 25 Jan 2007 Published: 25 Jan 2007

Breast Cancer Research 2007, 9:R10 (doi:10.1186/bcr1643)

This article is online at: http://breast-cancer-research.com/content/9/1/R10

(C) 2007 Satram-Hoang et al.; licensee BioMed Central Ltd.

This is an open access article distributed under the terms of the Creative Commons Attribution License (http://creativecommons.org/licenses/by/2.0), which permits unrestricted use, distribution, and reproduction in any medium, provided the original work is properly cited.

\begin{abstract}
Introduction A retrospective registry-based cohort study was conducted to examine the risk of second primary cancer following the occurrence of breast cancer in males.

Methods Data obtained from the California Cancer Registry in the period 1988 to 2003 included 1,926 men aged 85 years and younger diagnosed with a first primary breast cancer. Person-year analysis was applied to determine the risk of second primary cancers after the occurrence of a first primary breast cancer. The effects of age, race, and time since the first breast cancer diagnosis were assessed.
\end{abstract}

Results Of the 1,926 male breast cancer cases, 221 (11.5\%) developed a second primary cancer. Men with first incidence of breast cancer have a significantly higher risk of second cancer (standardized incidence ratio $(\mathrm{SIR})=1.16,95 \%$ confidence interval $(\mathrm{Cl})=1.01-1.32)$. The risk of a second site-specific cancer is elevated for breast cancer $(\mathrm{SIR}=52.12,95 \% \mathrm{Cl}=$ 31.83-80.49), cutaneous melanoma ( $\mathrm{SIR}=2.98,95 \% \mathrm{Cl}=$ 1.63-5.00) and stomach cancer (SIR $=2.11,95 \% \mathrm{Cl}=1.01-$ 3.88). There is a general tendency towards higher risks of second malignancies among younger men compared to older men and the risk increased with the passage of time.

Conclusion Male breast cancer patients should be monitored carefully for the occurrence of second primary cancers, especially a second primary breast cancer.

\section{Introduction}

Studying the occurrence of second primary cancers holds important implications for cancer etiology and preventive interventions. An association between a first and second cancer could indicate common host factors (genetic abnormalities, immune function and hormonal imbalances), shared environmental and/or occupational exposures, shared lifestyle factors, the effects of treatment for the first cancer [1,2], hereditary cancer syndromes [3], or even gene-environment interactions. Early age of onset of cancer, family history of disease, bilateral disease, and multiple primary cancers are hallmarks of hereditary cancer [3]. In some cases, the diagnosis of a rare cancer or cancer in the less usually affected sex, for example, male breast cancer (MBC), may also indicate hereditary cancer risk [3]. An awareness of multiple primary cancer syndromes can potentially influence the use of screening and sensitivity of screening in organs susceptible to multiple primary cancers, enabling early detection.
Three studies to date have investigated the risk of developing a second malignancy in MBC patients [4-6]. The first study evaluated the risk of subsequent breast cancer among 457 Swedish men, and reported a 93-fold excess risk for a second breast cancer [4]. Auvinen and colleagues [5] utilized the National Cancer Institute's Surveillance and Epidemiology End Results (SEER) data for 1,788 men and found a 30-fold excess risk of a second breast cancer and a 2-fold excess risk of cutaneous melanoma. The third study, by Hemminki and colleagues [6], pooled 3,409 MBC patients from 13 cancer registries around the world. An excess risk of second primary malignancy affecting the small intestine, rectum, pancreas, lymphohematopoietic system, prostate, and non-melanoma skin was elucidated [6]. The present study will attempt to confirm these findings and examine the relationships between observed multiple primaries, which may indicate a common etiology.

$\overline{\mathrm{CCR}}=$ California Cancer Registry $\mathrm{Cl}=$ confidence interval; $\mathrm{MBC}=$ male breast cancer; $\mathrm{SIR}=$ standardized incidence ratio. 


\section{Materials and methods}

A registry-based cohort of men previously diagnosed with first primary breast cancer was followed through time to compare their subsequent cancer experience to the number of cancers that would be expected based on incidence rates for the general California male population. The data were obtained from the California Cancer Registry (CCR), California's statewide population-based cancer surveillance system. The CCR is a collaborative effort involving the California Department of Health Services, ten regional registries, hospitals, cancer researchers throughout the nation, and the Public Health Institute. It collects information about all cancers diagnosed in California (except basal and squamous cell carcinoma of the skin and carcinoma in situ of the cervix). The database includes information on demographics, tumor characteristics (stage, grade, histology, laterality, behavior, and hormone receptor status), treatment, survival, and reporting hospital type.

The present study includes 1,926 males aged 85 years or less diagnosed with first primary breast cancer between 1 January 1988 and 31 October 2003, registered at the CCR. A second primary cancer was defined in this study as a malignant metachronous tumor that developed at least two months after first primary male breast cancer diagnosis. There were 221 (11.5\%) second primaries diagnosed in this cohort of men during the study period. Synchronous tumors occurring less than two months from first primary breast cancer were excluded in order to control for detection bias due to diagnostic methodology and also to be consistent with prior research conducted in the same geographic region [5]. Ninety-three percent of the cohort received surgery. In addition, 25\% underwent adjuvant hormone therapy, 24\% chemotherapy, and $20 \%$, radiation therapy, while $19 \%$ of the cohort had some combination therapy. No men were excluded from the analysis due to missing data as information regarding second malignancy, date of diagnosis and date of last contact or death were available for all patients.

For the purposes of rate adjustment, five-year age groups, resulting in 18 age categories, were used in calculating the expected number of cases. Race/ethnicity was categorized into five mutually exclusive groups: non-Hispanic white, Black, Hispanic, Asian/Pacific Islander, and other/unknown. To calculate the expected number of cancers for the other/unknown group, we used the incidence rates of all others combined. The calendar period was classified in five-year categories of diagnosis: 1988 to 1992,1993 to 1997 , and 1998 to 2003. Tumor site codes in accordance with SEER definitions for breast, prostate, colorectal, lung and bronchus, bladder, melanoma, and stomach cancer were obtained from the CCR [7]. The unit of analysis in our study was person/days at risk in order to maximize use of fractions of years if applicable. Person-years of observation were calculated two months from the date of breast cancer diagnosis up to and including age 85, the date of the second primary cancer, date of last contact or death, or study end (31 December 2003), whichever came first.

\section{Statistical analysis}

All statistical analysis conducted utilized SAS v 9.1 software. (SAS Institute Inc., SAS Campus Drive, Cary, North Carolina 27513, USA) Using the frequency procedure in SAS, the distribution of risk factors of interest among cohort members (Table 1) was evaluated. Chi-square analysis for categorical data and $t$-test for continuous data were used to compare the characteristics between patients who subsequently developed a second primary to those who did not (Table 1). Differences with a probability of $p<0.05$ were considered statistically significant.

Person-years analysis, adjusted for age, race, calendar period, and tumor site, was used to calculate the standardized incidence ratio (SIR) (Tables 2 to 5). The SIR is a comparison of the incidence of second primary tumors among study patients (observed) with the incidence of the same tumors in the general population of California males (expected). Calculation of the expected numbers of second primaries was accomplished by applying sex, five-year age, race, calendar period and sitespecific incidence rates from the general population of California males to the person-years at risk in the study population. To assess statistical significance, exact 95\% confidence intervals $(\mathrm{Cl})$ were computed around the SIR assuming that the observed number of second cancers followed a Poisson distribution.

\section{Results}

The characteristics of men diagnosed with first primary breast cancer are shown in Table 1. The cohort contained a total of 1,926 men of which 221 (11.47\%) subsequently developed a second metachronous malignancy. Approximately $68 \%$ of the cohort were 60 years of age or older. Patients who developed a second cancer were older (mean age $=66.90$ ) compared to patients who did not experience a subsequent cancer diagnosis (mean age $=64.16)(p=0.0002)$. The mean and median follow-up times for this cohort were 4.39 and 3.36 years, respectively, with no overall significant difference in follow-up time between the two groups. The majority of cases were non-Hispanic white $(76 \%)$ with all other races (blacks, Hispanics, Asians and other/unknown) making up the remainder of the population.

The overall SIRs for second malignancy by tumor site, controlling for age, race and calendar period, are shown in Table 2 for sites where at least ten cases were recorded. The observed number of second primary malignancies was 221 compared to 190.42 expected, thereby producing an SIR of $1.16(95 \% \mathrm{CI}$ $=1.01-1.32$ ), which shows an excess risk of $16 \%$. The excess risk of subsequent cancer decreased to $5 \%$ when second breast cancer was excluded and the result is not statistically significant. Overall, a significant excess of second 
Table 1

\begin{tabular}{|c|c|c|c|c|}
\hline Characteristic & No second cancer & Second cancer & Total & $P$ value \\
\hline Age (mean years (SD)) & $64.16(12.90)$ & $66.90(9.72)$ & $64.47(12.61)$ & 0.0002 \\
\hline Follow-up (mean years (SD)) & $4.39(3.74)$ & $4.38(3.31)$ & $4.39(3.69)$ & 0.9405 \\
\hline Age (median years (IQR) & $66.00(55.00-74.00)$ & $68.00(61.00-73.00)$ & $66.00(56.00-74.00)$ & \\
\hline Follow-up (median years (IQR) & $3.35(1.33-6.69)$ & $3.39(1.46-6.82)$ & $3.36(1.33-6.72)$ & \\
\hline \multicolumn{5}{|l|}{ Age (no. of subjects (percent)) } \\
\hline$<60$ years & $577(33.84)$ & $41(18.55)$ & $618(32.09)$ & $<0.0001$ \\
\hline 60 to 69 years & $458(26.86)$ & $89(40.27)$ & $547(28.04)$ & \\
\hline $70+$ years & $670(39.30)$ & $91(41.18)$ & $761(39.51)$ & \\
\hline \multicolumn{5}{|c|}{ Follow-up (no. of subjects (percent)) } \\
\hline$<1$ year & $342(20.06)$ & $42(19.00)$ & $384(19.94)$ & 0.4921 \\
\hline 1 to 5 years & $731(42.87)$ & $88(39.82)$ & $819(42.52)$ & \\
\hline$>5$ years & $632(37.07)$ & $91(41.18)$ & $723(37.54)$ & \\
\hline \multicolumn{5}{|l|}{ Race (no. of subjects (percent)) } \\
\hline Non-Hispanic white & $1,272(74.60)$ & $182(82.35)$ & $1,454(75.49)$ & 0.0117 \\
\hline Other & $433(25.40)$ & $39(17.65)$ & $472(24.51)$ & \\
\hline Total (no. of subjects (percent)) & 1,705 (88.53) & $221(11.47)$ & $1,926(100.00)$ & \\
\hline
\end{tabular}

A $p$ value $<0.05$ means statistically significant. IQR, interquartile range; SD, standard deviation.

primary was noted for breast cancer $(\mathrm{SIR}=52.12,95 \% \mathrm{Cl}=$ 31.83-80.49), cutaneous melanoma (SIR $=2.98,95 \% \mathrm{Cl}=$ 1.63-5.00), and stomach cancer $(\mathrm{SIR}=2.11,95 \% \mathrm{Cl}=$ $1.01-3.88)$.

The effect of diagnostic age on risk of subsequent cancer is presented in Table 3. The SIR or risk ratio for all malignancies combined (breast included and breast excluded) was highest in the younger population. A similar pattern was also observed for second breast cancer with higher excess risks starting in the $<60$ years age group and decreasing with increasing age. A significant excess of skin melanoma $(\mathrm{SIR}=3.18,95 \% \mathrm{Cl}=$ 1.17-6.93) was noted among men 70 years or older. In patients diagnosed between 60 and 69 years, a 2-fold increased risk of colorectal cancer was observed. Patients 70 years or older experienced a lower risk of lung and bronchus cancer $(\mathrm{SIR}=0.47,95 \% \mathrm{Cl}=0.19-0.97)$.

The effect of race on subsequent cancer risk, controlling for age and calendar period, is shown in Table 4. The 39 observed second primaries in the 'other' race/ethnic category comprise 15 black, 17 Hispanic and 7 Asian/Pacific Island men. Overall, non-Hispanic whites (SIR $=1.19,95 \% \mathrm{Cl}=$ 1.02-1.38) showed a significant excess of subsequent cancers. When breast was excluded, the excess of second prima- ries was no longer observed. Second breast cancer is elevated in both racial/ethnic categories. However, the excess risk was more prominent in the 'other' ethnic background compared to non-Hispanic whites. The increased risk of second primary breast cancer among the 'other' racial/ethnic category is largely due to the risk among blacks. The risk of melanoma among non-Hispanic white men was three-fold that expected. A significant excess in stomach cancer was observed in nonHispanic white males (SIR $=2.53,95 \% \mathrm{Cl}=1.09-4.99)$.

The SIRs for second malignancy by length of time after breast cancer diagnosis, controlling for age, race and calendar period, is shown in Table 5. The risk of all malignancies combined was significantly lower than expected in the first year of follow-up ( $\mathrm{SIR}=0.74,95 \% \mathrm{Cl}=0.53-0.99)$ and higher than expected after 5 years of follow-up $(\mathrm{SIR}=1.63,95 \% \mathrm{Cl}=$ 1.31-2.00). When breast cancer was excluded, the risk was $21 \%$ lower than expected in the first 5 years after diagnosis, but later increased to $45 \%$ after 5 years of follow-up. Second breast cancer was higher in each follow-up category, with the highest risk after five years of follow-up. A higher SIR was observed after 5 years from diagnosis for bladder cancer (SIR $=2.89,95 \% \mathrm{Cl}=1.49-5.05)$. Melanoma was in excess for 2 follow-up periods: 1 to 5 years $(\mathrm{SIR}=2.68,95 \% \mathrm{Cl}=1.08-$ $5.53)$ and $>5$ years $(\mathrm{SIR}=4.15,95 \% \mathrm{Cl}=1.52-9.02)$. Lung 
Breast Cancer Research Vol 9 No 1 Satram-Hoang et al.

Table 2

Risk of second primary cancer among men with first primary breast cancer

\begin{tabular}{|c|c|c|c|c|c|}
\hline Cancer site & $\mathrm{N}$ & PERYR & OBS & EXP & SIR (95 percent $\mathrm{Cl})$ \\
\hline All malignancies, breast included & 1,926 & $8,460.08$ & 221 & 190.42 & $1.16(1.01-1.32)$ \\
\hline All malignancies, breast excluded & 1,926 & $8,529.63$ & 201 & 191.63 & $1.05(0.91-1.20)$ \\
\hline Prostate & 1,926 & $8,803.74$ & 69 & 72.30 & $0.95(0.74-1.21)$ \\
\hline Second breast & 1,906 & $8,947.89$ & 20 & 0.38 & $52.12(31.83-80.49)$ \\
\hline Colorectal & 1,926 & $9,025.49$ & 26 & 22.64 & $1.15(0.75-1.68)$ \\
\hline Lung and bronchus & 1,926 & $9,065.75$ & 23 & 32.76 & $0.70(0.45-1.05)$ \\
\hline Bladder & 1,926 & $9,031.02$ & 20 & 13.46 & $1.49(0.91-2.29)$ \\
\hline Melanoma ${ }^{a}$ & 1,454 & $6,971.11$ & 14 & 4.69 & $2.98(1.63-5.00)$ \\
\hline Stomach & 1,926 & $9,074.43$ & 10 & 4.74 & $2.11(1.01-3.88)$ \\
\hline
\end{tabular}

Bold numbers indicate that the 95 percent confidence interval $(\mathrm{Cl})$ does not include 1.00. aNon-Hispanic whites only. EXP, expected; N, number of subjects; OBS, observed; PERYR, person years at risk; SIR, standardized incidence ratios.

and bronchus cancer was protective in the first five years after diagnosis. We also analyzed the data stratified by treatment type and subsequent cancer risk. We did not find any statistical associations with the risk of second cancers.

After more than five years had elapsed, significant excess risks were associated with men in the younger age categories

Table 3
(Table 5). The risk was 3-fold in men under 60 and 2 -fold in men 60 to 69 years of age at diagnosis. A $62 \%$ lower risk was noted in men 60 to 69 years of age within the first year of follow-up time.

Risk of second primary cancer by age at first primary male breast cancer diagnosis

\begin{tabular}{|c|c|c|c|c|c|c|c|c|c|c|c|c|c|c|c|}
\hline \multirow{3}{*}{ Cancer site } & \multicolumn{15}{|c|}{ Age (years) } \\
\hline & \multicolumn{5}{|c|}{$<60$} & \multicolumn{5}{|c|}{60 to 69} & \multicolumn{5}{|c|}{$\geq 70$} \\
\hline & $\mathrm{N}$ & PERYR & OBS & EXP & $\begin{array}{c}\text { SIR } \\
\text { (95 percent } \mathrm{Cl} \text { ) }\end{array}$ & $\mathrm{N}$ & PERYR & OBS & EXP & $\begin{array}{c}\text { SIR } \\
\text { (95 percent } \mathrm{Cl} \text { ) }\end{array}$ & $\mathrm{N}$ & PERYR & OBS & EXP & $\begin{array}{c}\text { SIR } \\
\text { (95 percent } \mathrm{Cl} \text { ) }\end{array}$ \\
\hline $\begin{array}{l}\text { All, breast } \\
\text { included }\end{array}$ & 618 & $2,912.85$ & 41 & 28.08 & $\begin{array}{c}1.42 \\
(1.02-1.94)\end{array}$ & 547 & $2,681.23$ & 89 & 72.35 & $\begin{array}{c}1.24 \\
(1.00-1.53)\end{array}$ & 761 & $2,866.01$ & 91 & 89.99 & $\begin{array}{c}1.01 \\
(0.81-1.24)\end{array}$ \\
\hline $\begin{array}{l}\text { All, breast } \\
\text { excluded }\end{array}$ & 618 & $2,929.25$ & 36 & 28.29 & $\begin{array}{c}1.24 \\
(0.86-1.72)\end{array}$ & 547 & $2,716.56$ & 80 & 73.08 & $\begin{array}{c}1.11 \\
(0.88-1.38)\end{array}$ & 761 & $2,883.83$ & 85 & 90.26 & $\begin{array}{c}0.94 \\
(0.75-1.16)\end{array}$ \\
\hline Prostate & 618 & $2,982.99$ & 15 & 8.41 & $\begin{array}{c}1.78 \\
(1.00-2.94)\end{array}$ & 547 & $2,826.47$ & 27 & 29.32 & $\begin{array}{c}0.92 \\
(0.61-1.34)\end{array}$ & 761 & $2,994.29$ & 27 & 34.56 & $\begin{array}{c}0.78 \\
(0.51-1.14)\end{array}$ \\
\hline $\begin{array}{l}\text { Second } \\
\text { breast }\end{array}$ & 605 & $2,992.73$ & 5 & 0.06 & $\begin{array}{c}\mathbf{8 1 . 3 8} \\
(26.42-189.92)\end{array}$ & 543 & $2,871.22$ & 9 & 0.14 & $\begin{array}{c}\mathbf{6 4 . 2 3} \\
(29.37-121.92)\end{array}$ & 758 & $3,083.94$ & 6 & 0.18 & $\begin{array}{c}32.98 \\
(12.09-71.68)\end{array}$ \\
\hline Colorectal & 618 & $3,047.87$ & 3 & 3.11 & $\begin{array}{c}0.96 \\
(0.20-2.82)\end{array}$ & 547 & 2,891.37 & 15 & 8.19 & $\begin{array}{c}1.83 \\
(1.03-3.02)\end{array}$ & 761 & $3,086.25$ & 8 & 11.34 & $\begin{array}{c}0.71 \\
(0.30-1.39)\end{array}$ \\
\hline $\begin{array}{l}\text { Lung and } \\
\text { bronchus }\end{array}$ & 618 & $3,053.53$ & 3 & 5.15 & $\begin{array}{c}0.58 \\
(0.12-1.70)\end{array}$ & 547 & $2,902.69$ & 13 & 12.81 & $\begin{array}{c}1.02 \\
(0.54-1.74)\end{array}$ & 761 & $3,109.52$ & 7 & 14.80 & $\begin{array}{c}\mathbf{0 . 4 7} \\
(0.19-0.97)\end{array}$ \\
\hline Bladder & 618 & $3,041.90$ & 3 & 1.62 & $\begin{array}{c}1.85 \\
(0.38-5.41)\end{array}$ & 547 & $2,901.04$ & 6 & 4.87 & $\begin{array}{c}1.23 \\
(0.45-2.68)\end{array}$ & 761 & $3,088.07$ & 11 & 6.97 & $\begin{array}{c}1.58 \\
(0.79-2.82)\end{array}$ \\
\hline Melanoma ${ }^{a}$ & 419 & $2,166.33$ & 3 & 1.09 & $\begin{array}{c}2.74 \\
(0.57-8.01)\end{array}$ & 427 & $2,358.83$ & 5 & 1.72 & $\begin{array}{c}2.92 \\
(0.95-6.80)\end{array}$ & 686 & $2,445.95$ & 6 & 1.89 & $\begin{array}{c}3.18 \\
(1.17-6.93)\end{array}$ \\
\hline Stomach & 618 & $3,054.70$ & 0 & 0.66 & $\begin{array}{c}0.00 \\
(0.00-4.54)\end{array}$ & 547 & $2,909.55$ & 4 & 1.66 & $\begin{array}{c}2.41 \\
(0.66-6.16)\end{array}$ & 761 & $3,110.18$ & 6 & 2.42 & $\begin{array}{c}2.48 \\
(0.91-5.40)\end{array}$ \\
\hline
\end{tabular}

Bold numbers indicate that the 95 percent confidence interval $(\mathrm{Cl})$ does not include 1.00. aNon-Hispanic whites only. EXP, expected; N, number of subjects; OBS, observed; PERYR, person years at risk; SIR, standardized incidence ratios. 
Table 4

Risk of second primary cancer after first primary male breast cancer diagnosis by race

\begin{tabular}{|c|c|c|c|c|c|c|c|c|c|c|}
\hline \multirow[b]{3}{*}{ Cancer Site } & \multicolumn{10}{|c|}{ Race } \\
\hline & \multicolumn{5}{|c|}{ Non-Hispanic white } & \multicolumn{5}{|c|}{ Other } \\
\hline & $\mathrm{N}$ & PERYR & OBS & EXP & SIR (95 percent Cl) & $\mathrm{N}$ & PERYR & OBS & EXP & SIR (95 percent Cl) \\
\hline All, breast included & 1,454 & $6,523.25$ & 182 & 153.02 & $1.19(1.02-1.38)$ & 472 & $1,936.84$ & 39 & 37.40 & $1.04(0.74-1.43)$ \\
\hline All, breast excluded & 1,454 & $6,572.88$ & 168 & 153.92 & $1.09(0.93-1.27)$ & 472 & $1,956.75$ & 33 & 37.71 & $0.88(0.60-1.23)$ \\
\hline Prostate & 1,454 & $6,801.52$ & 55 & 57.34 & $0.96(0.72-1.25)$ & 472 & $2,002.21$ & 14 & 14.96 & $0.94(0.51-1.57)$ \\
\hline Second breast & 1,437 & $6,908.47$ & 14 & 0.31 & $44.73(24.45-75.04)$ & 469 & $2,039.42$ & 6 & 0.07 & $84.83(31.13-184.63)$ \\
\hline Colorectal & 1,454 & $6,976.41$ & 22 & 18.32 & $1.20(0.75-1.82)$ & 472 & $2,049.09$ & 4 & 4.32 & $0.93(0.25-2.37)$ \\
\hline Lung and bronchus & 1,454 & 6,999.32 & 19 & 26.40 & $0.72(0.43-1.12)$ & 472 & $2,066.43$ & 4 & 6.36 & $0.63(0.17-1.61)$ \\
\hline Bladder & 1,454 & $6,963.65$ & 19 & 11.93 & $1.59(0.96-2.49)$ & 472 & $2,067.37$ & 1 & 1.53 & $0.65(0.02-3.65)$ \\
\hline Melanoma ${ }^{a}$ & 1,454 & $6,971.11$ & 14 & 4.69 & $2.98(1.63-5.00)$ & - & - & - & - & - \\
\hline Stomach & 1,454 & $7,013.32$ & 8 & 3.16 & $2.53(1.09-4.99)$ & 472 & $2,061.12$ & 2 & 1.58 & $1.27(0.15-4.57)$ \\
\hline
\end{tabular}

Bold numbers indicate that the 95 percent confidence interval $(\mathrm{Cl})$ does not include 1.00. aNon-Hispanic whites only. EXP, expected; $\mathrm{N}$, number of subjects; OBS, observed; PERYR, person years at risk; SIR, standardized incidence ratios.

\section{Discussion}

Our study shows that men diagnosed with a first primary breast cancer have a $16 \%$ increased risk of developing a new primary cancer in comparison with men in the general population. The prior US study, based on the geographic areas included in the SEER program, did not find an overall excess of second primary cancer [5]. That study accounted for roughly $50 \%$ of California.

Breast cancers in men are characteristic of the BRCA2 phenotype, which accounts for approximately $15 \%$ of all MBC [8]. Founder BRCA2 mutations contribute even higher prevalence rates of MBC in countries like Iceland, Sweden, Hungary, and also in Ashkenazi Jewish populations [8]. The high risks for the presence of bilateral breast disease or multiple disease sites in one organ, especially among younger men, in the current investigation as well as in prior investigations are a likely indicator of a hereditary cancer syndrome $[3,9]$.

Male tumors related to $B R C A 1$ and $B R C A 2$ include breast, melanoma, stomach, prostate, colon and pancreatic cancer [8]. The risk is even more pronounced among carriers younger than 65 for melanoma, stomach, and prostate cancer $[10,11]$. Although in $\mathrm{MBC}$ a second breast cancer has the strongest association, melanoma was in excess consistently throughout the analysis and also appears to have a high relative risk, confirmed by the prior US investigation [5], but uncorroborated by Hemminki and colleagues [6]. The excess risk of melanoma was more prominent among older men, in non-Hispanic whites, and after one year of follow-up. Epidemiological studies on malignant melanoma and breast cancer suggest the influence of steroid hormones on the etiology and development of these tumors. Melanoma and breast cancer are more common in women than men, implicating the role of female hormones and further strengthening the argument of a common etiological pathway between the two. A high socio-economic status is another shared risk factor [12], but this may represent a proxy for race, as non-Hispanic whites have higher rates of both diseases. In regards to shared genetic susceptibility, both the CDKN2A mutation and the BRCA2 mutation are linked. Families with the CDKN2A mutation have an increased risk not only of multiple melanomas and pancreatic carcinoma but also of breast cancer $[13,14]$. Further, an excess of melanoma has been reported in 173 BRCA2 families, particularly among carriers younger than 65 [10].

We observed an overall excess of stomach cancer, a result inconsistent in the two prior investigations $[5,6]$. Obesity is one of the main risk factors for gastric cancer $[15,16]$ and MBC [17-21] and this common risk factor may, to some degree, explain the relationship between the two.

The risk of lung cancer was lower than expected for men $\geq 70$ years of age during the first 5 years of follow-up after their breast cancer. The observed lower number of lung cancer cases may be an underestimate due to potential competing risk of dying due to other conditions.

We examined treatment effects (not shown) on risk of subsequent cancer. There was no statistical association of subsequent cancer risk with prior hormone therapy, radiation therapy, or chemotherapy on risk with the exception of second breast cancer. The increased SIR for second primary breast cancer in patients with and without prior hormone therapy and chemotherapy is more likely to be related to the rarity of breast cancer in men, which causes each observed case to contribute a substantial portion to the risk estimate. In addition, the increased risk of second primary breast cancer observed with 
Table 5

Risk of second primary cancer by time after first primary male breast cancer

\begin{tabular}{|c|c|c|c|c|c|c|c|c|c|c|c|c|c|c|c|}
\hline \multirow[b]{2}{*}{ Cancer site } & \multicolumn{5}{|c|}{$<1$ year } & \multicolumn{5}{|c|}{1 to 5 years } & \multicolumn{5}{|c|}{$>5$ years } \\
\hline & $\mathrm{N}$ & PERYR & OBS & EXP & $\begin{array}{c}\text { SIR } \\
\text { (95 percentCl) }\end{array}$ & $\mathrm{N}$ & PERYR & OBS & EXP & $\begin{array}{c}\text { SIR } \\
\text { (95 percentCl) }\end{array}$ & $\mathrm{N}$ & PERYR & OBS & EXP & $\begin{array}{c}\text { SIR } \\
\text { (95 percentCl) }\end{array}$ \\
\hline $\begin{array}{l}\text { All, breast } \\
\text { included }\end{array}$ & 1,926 & $1,653.87$ & 42 & 57.12 & $\begin{array}{c}0.74 \\
(0.53-0.99)\end{array}$ & 1,884 & 4332.66 & 88 & 101.51 & $\begin{array}{c}0.87 \\
(0.70-1.07)\end{array}$ & 1,796 & $\begin{array}{c}2,469.3 \\
4\end{array}$ & 91 & 55.92 & $\begin{array}{c}1.63 \\
(1.31-2.00)\end{array}$ \\
\hline $\begin{array}{l}\text { All, breast } \\
\text { excluded }\end{array}$ & 1,926 & $1,655.89$ & 38 & 57.09 & $\begin{array}{c}0.67 \\
(0.47-0.91)\end{array}$ & 1,888 & 4359.60 & 81 & 101.92 & $\begin{array}{c}0.79 \\
(0.63-0.99)\end{array}$ & 1,807 & $\begin{array}{c}2,509.9 \\
0\end{array}$ & 82 & 56.64 & $\begin{array}{c}1.45 \\
(1.15-1.80)\end{array}$ \\
\hline Prostate & 1,926 & $1,666.28$ & 14 & 20.83 & $\begin{array}{c}0.67 \\
(0.37-1.13)\end{array}$ & 1,912 & 4450.10 & 27 & 37.81 & $\begin{array}{c}0.71 \\
(0.47-1.04)\end{array}$ & 1,885 & $\begin{array}{c}2,683.0 \\
8\end{array}$ & 28 & 21.89 & $\begin{array}{c}1.28 \\
(0.85-1.85)\end{array}$ \\
\hline Second breast & 1,926 & $1,654.10$ & 4 & 0.11 & $\begin{array}{c}34.90 \\
(9.51-89.35)\end{array}$ & 1,922 & 4478.09 & 7 & 0.21 & $\begin{array}{c}33.77 \\
(13.58-69.57)\end{array}$ & 1,915 & $\begin{array}{c}2,811.4 \\
3\end{array}$ & 9 & 0.12 & $\begin{array}{c}75.85 \text { (34.68- } \\
143.99)\end{array}$ \\
\hline Colorectal & 1,926 & $1,670.38$ & 5 & 6.23 & $\begin{array}{c}0.80 \\
(0.26-1.87)\end{array}$ & 1,921 & 4524.94 & 11 & 11.66 & $\begin{array}{c}0.94 \\
(0.47-1.69)\end{array}$ & 1,910 & $\begin{array}{c}2,825.8 \\
7\end{array}$ & 10 & 7.11 & $\begin{array}{c}1.41 \\
(0.67-2.59)\end{array}$ \\
\hline $\begin{array}{l}\text { Lung and } \\
\text { bronchus }\end{array}$ & 1,926 & $1,672.78$ & 4 & 9.23 & $0.43(0.12-1.11)$ & 1,922 & 4540.41 & 6 & 17.21 & $\begin{array}{c}0.35 \\
(0.13-0.76)\end{array}$ & 1,916 & $\begin{array}{c}2,848.2 \\
5\end{array}$ & 13 & 10.82 & $\begin{array}{c}1.20 \\
(0.64-2.05)\end{array}$ \\
\hline Bladder & 1,926 & $1,671.12$ & 4 & 3.73 & $1.07(0.29-2.74)$ & 1,922 & 4534.16 & 4 & 6.97 & $0.57(0.16-1.47)$ & 1,918 & $\begin{array}{c}2,821.4 \\
3\end{array}$ & 12 & 4.15 & $2.89(1.49-5.05)$ \\
\hline Melanoma $^{\mathrm{a}}$ & 1,454 & $1,276.50$ & 1 & 1.48 & $\begin{array}{c}0.68 \\
(0.02-3.77)\end{array}$ & 1,453 & 3491.48 & 7 & 2.61 & $\begin{array}{c}2.68 \\
(1.08-5.53)\end{array}$ & 1,446 & $\begin{array}{c}2,199.8 \\
1\end{array}$ & 6 & 1.45 & $\begin{array}{c}4.15 \\
(1.52-9.02)\end{array}$ \\
\hline Stomach & 1,926 & $1,672.98$ & 2 & 1.30 & $\begin{array}{c}1.54 \\
(0.19-5.58)\end{array}$ & 1,924 & 4545.53 & 4 & 2.43 & $\begin{array}{c}1.65 \\
(0.45-4.21)\end{array}$ & 1,920 & $\begin{array}{c}2,851.6 \\
1\end{array}$ & 4 & 1.50 & $\begin{array}{c}2.66 \\
(0.72-6.81)\end{array}$ \\
\hline \multicolumn{16}{|l|}{ Age (years) } \\
\hline$<60$ & 618 & 531.05 & 6 & 5.85 & $\begin{array}{c}1.02 \\
(0.38-2.23)\end{array}$ & 612 & 1445.16 & 12 & 12.41 & $\begin{array}{c}0.89 \\
(0.44-1.59)\end{array}$ & 600 & 935.26 & 23 & 8.18 & $\begin{array}{c}2.81 \\
(1.78-4.22)\end{array}$ \\
\hline 60 to 69 & 547 & 491.85 & 7 & 18.38 & $\begin{array}{c}0.38 \\
(0.15-0.78)\end{array}$ & 540 & 1329.22 & 36 & 35.41 & $\begin{array}{c}1.04 \\
(0.74-1.44)\end{array}$ & 504 & 858.89 & 46 & 23.64 & $\begin{array}{c}1.95 \\
(1.42-2.60)\end{array}$ \\
\hline $70+$ & 761 & 630.97 & 29 & 32.89 & $\begin{array}{c}0.88 \\
(0.59-1.27)\end{array}$ & 732 & 1558.27 & 40 & 53.69 & $\begin{array}{c}0.74 \\
(0.53-1.01)\end{array}$ & 692 & 675.19 & 22 & 24.10 & $\begin{array}{c}0.91 \\
(0.57-1.38)\end{array}$ \\
\hline
\end{tabular}

Bold numbers indicate that the 95 percent confidence interval $(\mathrm{Cl})$ does not include 1.00. aNon-Hispanic whites only. EXP, expected; $\mathrm{N}$, number of subjects; OBS, observed; PERYR, person years at risk; SIR, standardized incidence ratios.

a five year latency period may be attributable to advances in breast cancer diagnosis and treatment, which improve prognosis, and thus patients may live longer and are at a higher risk for second primary breast cancer.

The high rate of subsequent cancer among non-Hispanic whites may be due to better follow-up, better treatment or they may have a survival advantage to develop a second cancer. This is exemplified by the higher mean length of survival adjusted for age observed in non-Hispanic whites compared to other racial/ethnic groups. Based on time to death after breast cancer diagnosis, non-Hispanic whites experienced the highest mean survival of 4.49 years $(n=1,454)$, followed by 4.38 for Asian/Pacific Islanders $(n=107), 4.14$ for blacks ( $n$ $=157$ ) and 3.86 for Hispanics $(n=170)$ in this study. The excess of stomach cancer among non-Hispanic white males is unexpected as it is usually more prevalent in other racial/ethnic groups, particularly Asian/Pacific Islanders [22].

The overall risk of subsequent malignancies other than breast cancer was not significantly elevated, confirming the observations reported by Hemminki and colleagues [6]. The differences in risk estimates between investigations could be explained by several factors. First, there are important distinc- tions in racial/ethnic distribution between the Swedish populations (mostly Caucasian) and the diverse California population that may account for the discrepancy. Second, differences in screening practices, quality of healthcare, and access to and use of healthcare between the populations may also play a role. Thirdly, the variation of dietary, lifestyle and environment exposures, as well as genomic reactions to environmental exposures may play a role in the differences observed.

\section{Strengths and limitations}

A strength of the present study is that it is a registry-based analysis including a large number of cases of a rare cancer such as MBC. The data are of high quality as they are carefully controlled by the well-recognized, statewide, populationbased cancer registry in California. Because only one registry was used in this analysis the quality of data is consistent over time. Additionally, confounding variables such as age and race were controlled-for, while other studies did not control for the effects of race $[5,6]$. This could explain some of the contradictory results between investigations, making the findings of the present study more meaningful. 
The limitations of this study include the unavailable data on potentially confounding factors such as family history, genetic predisposition and environmental exposures. Also, about onethird of those that were diagnosed after 1998 were followed for less than five years, which may be insufficient time to record subsequent primaries as cancer typically has a long latency period. Conversely, because this cohort consists of cancer patients, they are more likely to be diagnosed with a second cancer due to increased patient awareness and increased surveillance compared to men in the general population. It is possible that the second primary breast cancers after first primary breast cancer may be misdiagnosed metastases. However, this is unlikely as we have excluded all tumors that do not follow the SEER guidelines for multiple primaries. We conducted a large number of comparisons and, therefore, we recognize that some of the results might be due to chance.

\section{Conclusion}

Our retrospective cohort study shows that MBC patients have a $16 \%$ higher risk of developing a second primary cancer than men in the general population, and the risk is more apparent in younger men. These results will have substantial medical implications for cancer patients as well as for relatives that are at risk of the disease. Medical interventions to address increased risk of second cancer include increased surveillance, chemoprevention, and prophylactic surgery. Future investigations should further explore the role of adjuvant hormonal, radiation, and chemotherapy with a longer follow-up period and larger patient population to better describe the risk involved. Other possible areas of future investigation could examine the risk of $\mathrm{MBC}$ after first primary melanoma and stomach cancer.

\section{Competing interests}

The authors declare that they have no competing interests.

\section{Authors' contributions}

SS designed and carried out the data analysis and drafted the manuscript. AZ helped guide the statistical analysis and edit the manuscript. HAC participated in the design of the study and helped edit the manuscript. All authors read and approved the final manuscript.

\section{Acknowledgements}

This research was supported by the National Institutes of Health, National Cancer Institute grant CA-58860 and the Lon V Smith Foundation grant LVS-35977. The collection of cancer incidence data used in this study was supported by the California Department of Health Services as part of the statewide cancer reporting program mandated by California Health and Safety Code Section 103885; the National Cancer Institute's Surveillance, Epidemiology and End Results Program under contract N01-PC-35136 awarded to the Northern California Cancer Center, contract N01-PC-35139 awarded to the University of Southern California, and contract N02-PC-15105 awarded to the Public Health Institute; and the Centers for Disease Control and Prevention's National Program of Cancer Registries, under agreement \#U55/ CCR921930-02 awarded to the Public Health Institute. The ideas and opinions expressed herein are those of the authors and endorsement by the State of California, Department of Health Services, the National Cancer Institute, and the Centers for Disease Control and Prevention or their contractors and subcontractors is not intended nor should be inferred.

\section{References}

1. Horn-Ross PL: Multiple primary cancers involving the breast. Epidemiol Rev 1993, 1:169-176.

2. Shapiro CL, Recht $A$ : Late effects of adjuvant therapy for breast cancer. J Natl Cancer Inst Monogr 1994, (16):101-112.

3. Frank TS: Hereditary cancer syndromes. Arch Pathol Lab Med 2001, 125:85-90.

4. Dong C, Hemminki K: Second primary breast cancer in men. Breast Cancer Res Treat 2001, 66:171-172.

5. Auvinen A, Curtis RE, Ron E: Risk of subsequent cancer following breast cancer in men. J Natl Cancer Inst 2002, 94:1330-1332.

6. Hemminki K, Scelo G, Boffetta P, Mellemkjaer L, Tracey E, Andersen A, Brewster DH, Pukkala E, McBride M, Kliewer EV, et al:: Second primary malignancies in patients with male breast cancer. Br J Cancer 2005, 92:1288-1292.

7. Kwong SL, Wright WE: Cancer in California Sacramento, CA: California Department of Health Services, Cancer Surveillance Section; 2003.

8. Liede A, Karlan BY, Narod SA: Cancer risks for male carriers of germline mutations in BRCA1 or BRCA2: a review of the literature. J Clin Oncol 2004, 22:735-742.

9. Marsh D, Zori R: Genetic insights into familial cancers-update and recent discoveries. Cancer Lett 2002, 181:125-164.

10. The Breast Cancer Linkage Consortium: Cancer risks in BRCA2 mutation carriers. J Nat/ Cancer Inst 1999, 91:1310-1316.

11. Thompson D, Easton DF, Breast Cancer Linkage Consortium: Cancer Incidence in BRCA1 mutation carriers. I Natl Cancer Inst 2002, 94:1358-1365.

12. Kirkpatrick CS, Lee JA, White E: Melanoma risk by age and socio-economic status. Int J Cancer 1990, 46:1-4.

13. Borg A, Sandberg T, Nilsson K, Johannsson O, Klinker M, Masback $A$, Westerdahl J, Olsson $\mathrm{H}$, Ingvar $\mathrm{C}$ : High frequency of multiple melanomas and breast and pancreas carcinomas in CDKN2A mutation-positive melanoma families. J Natl Cancer Inst 2000, 92:1260-1266.

14. Debniak T, Gorski B, Huzarski T, Byrski T, Cybulski C, Mackiewicz A, Gozdecka-Grodecka S, Gronwald J, Kowalska E, Haus O, et al: A common variant of CDKN2A (p16) predisposes to breast cancer. J Med Genet 2005, 42:763-765.

15. Vaughan TL, Davis S, Kristal A, Thomas DB: Obesity, alcohol, and tobacco as risk factors for cancers of the esophagus and gastric cardia: adenocarcinoma versus squamous cell carcinoma. Cancer Epidemiol Biomarkers Prev 1995, 4:85-92.

16. Chow WH, Blot WJ, Vaughan TL, Risch HA, Gammon MD, Stanford JL, Dubrow R, Schoenberg JB, Mayne ST, Farrow DC, et al.: Body mass index and risk of adenocarcinomas of the esophagus and gastric cardia. J Nat/ Cancer Inst 1998, 90:150-155.

17. Thomas DB, Jimenez LM, McTiernan A, Rosenblatt K, Stalsberg $\mathrm{H}$, Stemhagen A, Thompson WD, Curnen MG, Satariano W, Austin DF: Breast cancer in men: risk factors with hormonal implications. Am J Epidemiol 1992, 135:734-748.

18. Ewertz M, Holmberg L, Tretli S, Pedersen BV, Kristensen A: Risk factors for male breast cancer - a case-control study from Scandinavia. Acta Oncol 2001, 40:467-471.

19. Hsing AW, McLaughlin JK, Cocco P, Co Chien HT, Fraumeni JF Jr: Risk factors for male breast cancer (United States). Cancer Causes Control 1998, 9:269-275.

20. Johnson KC, Pan S, Mao Y, Canadian Cancer Registries Epidemiology Research Group: Risk factors for male breast cancer in Canada, 1994-1998. Eur J Cancer Prev 2002, 11:253-263.

21. Casagrande JT, Hanisch R, Pike MC, Ross RK, Brown JB, Henderson BE: A case-control study of male breast cancer. Cancer Res 1988, 48:1326-1330.

22. Kwong SL, Perkins Cl, Morris CR, Cohen R, Allen M, Wright WE: Cancer in California 1988-1999 Sacramento, CA: California Department of Health Services, Cancer Surveillance Section; 2001. 